\title{
ROBOT-ASSISTED MINIMALLY INVASIVE SOLO MITRAL VALVE OPERATION
}

Volkmar Falk, MD, Thomas Walther, MD, Rüdiger Autschbach, MD, PhD, Anno Diegeler, MD, Roberto Battellini, MD, and Friedrich W. Mohr, MD, PhD, Leipzig, Germany

This study tested the feasibility of minimally invasive solo mitral valve operations with a voice-controlled robotic device for videoscopic guidance.

Methods. In eight consecutive patients with nonischemic mitral valve disease, videoscopically guided mitral valve operations were performed with the port-access technique (Heartport, Inc., Redwood City, Calif.) and endoaortic clamping. ${ }^{1-3}$ After femorofemoral bypass was established, a 4 to $5 \mathrm{~cm}$ incision was made laterally in the fourth right intercostal space. A three-dimensional videoscope (Karl Zeiss, Oberkochen, Germany) was inserted through a $10 \mathrm{~mm}$ port at the second right intercostal space in the anterior axillary line and connected to a robotic arm (AESOP 2000; Computer Motion, Santa Barbara, Calif.) that was mounted to the operating table. Motion of the robot device was controlled by the surgeon with voice activation and simple one- or two-word commands. The left atrial retractor was inserted parasternally in the right sixth intercostal space and mounted to a passive manipulator arm (Medtronic DLP, Grand Rapids, Mich.) that stabilized the retractor in the desired position (Fig. 1).

Results. In all patients, uncomplicated minimally invasive solo mitral valve operations were accomplished with

From the Department of Cardiac Surgery, Heartcenter, University of Leipzig, Leipzig, Germany.

Received for publication July 21, 1997; accepted for publication Sept. 11, 1997.

Address for reprints: Volkmar Falk, MD, Klinik für Herzchirurgie, Universität Leipzig, Herzzentrum, Russenstraße 19, 04289 Leipzig, Germany.

J Thorac Cardiovasc Surg 1998;115:470-1

Copyright (c) 1998 by Mosby, Inc.

$0022-5223 / 98 \$ 5.00+0 \quad \mathbf{1 2 / 5 4} / \mathbf{8 6 1 9 2}$ robotically driven videoscopic guidance without the need for an additional assistant. No personnel other than the surgeon and a scrub nurse were necessary. The voicecontrolled AESOP 2000 robot provided an excellent and steady videoscopic picture. Compared with manually guided videoscopic assistance, the robot provided smoother and more precise movements and zooming maneuvers, resulting in superior exposure of all valvular and subvalvular structures. The ability of the robot to memorize and return to different positions automatically clearly enhanced exposure. Complex repair procedures were greatly facilitated, and overall performance of the surgeon was improved. The voice-controlled mode al-

Table I. Comparison of robot-assisted solo procedure with manually assisted port-access procedure

\begin{tabular}{lccc}
\hline & $\begin{array}{c}\text { Robot } \\
\text { assistance }\end{array}$ & $\begin{array}{c}\text { Manual } \\
\text { assistance }\end{array}$ & $\begin{array}{c}p \\
\text { Value }\end{array}$ \\
\hline$N$ & 8 & 20 & \\
Age (yr) & $56 \pm 16$ & $61 \pm 12$ & $0.12^{*}$ \\
LVEF (\%) & $59 \pm 18$ & $56 \pm 14$ & $0.36^{*}$ \\
MV reconstruction (\%) & 75 & 65 & $0.61 \dagger$ \\
Number of lens cleanings & $1.1 \pm 0.6$ & $5.2 \pm 2.2$ & $0.001^{*}$ \\
Number of personnel & $2 \ddagger$ & $4 \S$ & - \\
Operation time (min) & $141 \pm 17$ & $164 \pm 59$ & $0.15^{*}$ \\
Perfusion time (min) & $101 \pm 27$ & $118 \pm 61$ & $0.23^{*}$ \\
Ischemic time (min) & $46 \pm 14$ & $54 \pm 20$ & $0.15^{*}$ \\
\hline
\end{tabular}

$L V E F$, Left ventricular ejection fraction; $M V$, mitral value.

*Unpaired $t$ test.

$\dagger \chi^{2}$ test.

$¥$ Surgeon and scrub nurse.

§Surgeon, scrub nurse, and two assistants. 
lowed the surgeon to continue operating without interrupting the procedure to adjust the videoscope. Lens cleaning, frequently required with manual videoscopic guidance, was rarely necessary with the robotic device (Table I). As a result, operating time was slightly shorter than that achieved with a standard surgical team approach. Because of the small sample and other factors that affect overall operative time, this difference was not statistically significant (Table I). No technical mishaps occurred during the procedures. All patients had uneventful recoveries and were discharged with good functional results between postoperative days 5 and 9 .

Discussion. Minimally invasive mitral valve surgery with the port-access technique has been performed at our institution in 72 cases at this writing. Use of passive articulating arms to hold both the left atrial retractor and the videoscope made the potential for solo mitral valve operations obvious. However, the need for frequent adjustments to the videoscope distracted the surgeon and increased the time required for the procedure.

The AESOP 2000 has been applied successfully in laparoscopic procedures. ${ }^{4,5}$ This is the first report of its use in minimally invasive mitral valve procedures. The device allows a full range of movement and provides a steady visual field. In consequence, overall performance is enhanced. When this device is combined with the passive articulating arm that fixes the left atrial retractor, solo operations, without the need for an additional assistant, are possible with operating times close to those required for conventional mitral valve repair.

Removal and reinsertion of the scope for cleaning is a time-consuming process that results in a loss of concentration. A dramatic decrease in the number of lens cleanings observed with the robotic arm has led to decreased operating times in complex laparoscopic procedures. $^{4,5}$ In comparisons of robotic versus human manual videoscopic guidance, the robot performed with less inadvertent camera motion and rotation, leading to a much steadier visual field. ${ }^{4,5}$ Our study confirms these findings. Communication misunderstandings concerning the video image, frequent between surgeon and assistants, are avoided with the AESOP 2000 because the surgeon is able to position the scope exactly with simple voice commands. Because verbal control of the visual field is part of the normal concentration pattern of the operating surgeon, a voice-controlled robotic arm compares favorably with digitally or pedally controlled devices. Training for the robot, including comprehension of the range of motion and learning commands, is a 10-minute task.

The AESOP 2000 is a reliable surgical assistant that potentially eliminates the need for a human assistant to guide the scope in minimally invasive videoscopic mitral valve operations. It thus may affect the overall cost of these procedures. The single-arm robotic assistant has opened the door to solo cardiac operations.

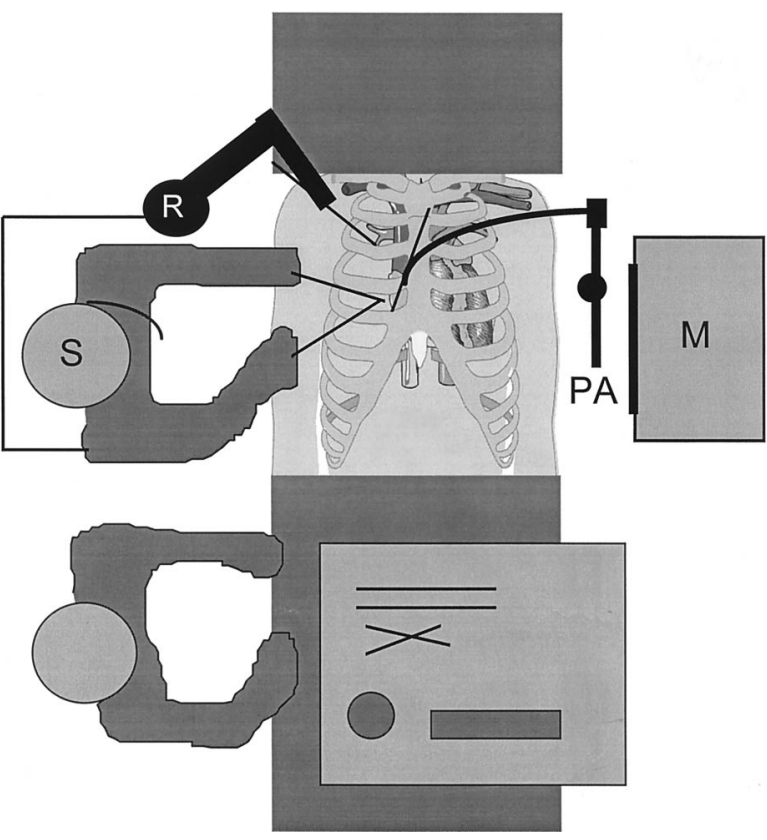

Fig. 1. Operative setting in minimally invasive solo mitral valve operation. The robotic arm $(R)$ that holds the three-dimensional videoscope is fixed at the operating table left of the surgeon $(S)$ and operated by voice control. The left atrial retractor is fixed by a passive articulating arm $(P A)$ that is mounted to the operating table opposite the surgeon. $M$, Video monitor.

\section{REFERENCES}

1. Pompili MF, Stevens JH, Burdon TA, Siegel LC, Peters WS, Ribakove GH, et al. Port-access mitral valve replacement in dogs. J Thorac Cardiovasc Surg 1996;112:1268-74.

2. Falk V, Walther T, Diegeler A, Autschbach R, Wendler R, van Son JAM, et al. Echocardiographic monitoring of minimally invasive mitral valve surgery using an endoaortic clamp. J Heart Valve Dis 1996;5:630-7.

3. Mohr FW, Falk V, Diegeler A, Walther T, van Son JAM, Autschbach R. Minimally invasive port-access mitral valve surgery. J Thorac Cardiovasc Surg. In press.

4. Geis WP, Kim HC, Mc Afee PC, Kang JG, Brennan EJ. Synergistic benefits of combined technologies in complex minimally invasive surgical procedures: clinical experience and educational processes. Surg Endosc 1996;10:1025-8.

5. Kavoussi LP, Moore RG, Adams JB, Partin AW. Comparison of robotic versus human laparoscopic camera control. J Urol 1994;154:2134-6. 